\title{
PALEOTEMPERATURE OF THE LAST INTERGLACIAL PERIOD BASED ON $\triangle 180$ OF STROMBUS BUBONIUS FROM THE WESTERN MEDITERRANEAN SEA
}

\author{
Cornu, S. ${ }^{a}$, Pätzold, J. ${ }^{b}$, Bard, E. ${ }^{a}$, Meco, J. ${ }^{c}$, Cuerda-Barcelo, J. ${ }^{d}$
}

\author{
a Laboratoires de Géosciences et d'Environement, JE DRED 192, Faculté de St Jérôme Université d' Aix-Marseille III, 13397 \\ Marseille Cedex 20, France \\ b Fachbereich Geowissenschaften, Universität Bremen, D 2800 Bremen 33, Germany \\ c Dept de Biologia, Universidad de Las Palmas de Gran Canaria, Campus de Tafira, Las Palmas, Spain \\ d Sociedad de Historia Natural de Baleares, Palma de Mallorca, Spain
}

\section{Abstract}

The objective of the present study is to quantify sea surface temperature (SST) by measuring $\delta 180$ in shells of Strombus bubonius. First we present data obtained from modern shells collected at different locations in the Gulf of Guinea where Strombus bubonius is now geographically restricted (islands of Corisso, Bioko and Pagalu). Next we give the results of our investigations of fossils found in two classical Mediterranean sites: Monastir in Tunisia and Palma Nova, a Pleistocene deposit on the island of Majorca. Both sites have been assigned an age corresponding to the last interglacial period (LIP) by stratigraphic correlation with terraces dated by the UTh method. The sampling scheme followed precisely the growth spiral of the mollusk shell in order to obtain time series of 3-4 years, depending on the size of the specimen. As expected, the $\delta 180$ records generally exhibit a cyclic pattern which can attributed of the seasonality of SST. $\delta 180$-SST's reconstructed for the modern shells are in rough agreement with SST values obtained from climatological maps, which suggests that Strombus shells may be useful in paleotemperature reconstructions. The difference between $\delta 180$ maxima and minima (isotopic seasonality) is generally in aggreement with the modern SST seasonality range inferred from climatological data. This $\delta 180$-SST seasonal temperature difference ranges from $2^{\circ} \mathrm{C}$ to $6^{\circ} \mathrm{C}$ for the modern shells from the Gulf of Guinea and from $7^{\circ} \mathrm{C}$ to $9^{\circ} \mathrm{C}$ for the Mediterranean fossils, which is not significantly different from modern seasonality at these locations. The $\delta 180$ records obtained from the fossils suggest that the SST's were higher by several ${ }^{\circ} \mathrm{C}$ during the LIP. However, the magnitude of this temperature difference is difficult to quantify precisely due to our lack of knowledge of the sea surface salinity (SSS) distribution during the LIP. We chose two different working hypotheses: (1) that the Mediterranean SSS's were the same as today, and (2) that the SSS's were typical for periods of sapropel deposition. Mean temperature differences of about $7^{\circ} \mathrm{C}$ and $3^{\circ} \mathrm{C}$ can be deduced under the first and the second working hypotheses, respectively. The second value is in agreement with other temperature proxies from marine and terrestrial environments which lends support to the second hypothesis. 